\title{
DO START AO GAME OVER: ANALISANDO NARRATIVAS DE APRENDIZAGEM DE INGLÊS COM JOGOS ELETRÔNICOS
}

\author{
Keila Mendes dos Santos* \\ Cleide Jane de Sa Araujo Costa ${ }^{* *}$
}

\begin{abstract}
Resumo: Este estudo objetiva investigar o processo de aprendizagem de estudantes de língua inglesa (LI), que assumem terem aprendido o idioma por meio da prática de jogos eletrônicos, especificamente os chamados jogos $\mathrm{MMORPG}_{2}$ e também destacar as estratégias adotadas pelos aprendizes ao longo do referido processo. Trata-se de uma pesquisa qualitativa que teve como participantes três estudantes de letras/inglês, gamers. Para coletar os dados foram utilizadas narrativas de aprendizagem nas quais os aprendizes relataram seu processo de construção do conhecimento em LI, partindo do contato com os jogos. A pesquisa teve por fundamento o seguinte questionamento: De que forma a prática de games do gênero MMORPG auxiliam no processo de aprendizagem da língua inglesa? Os resultados demonstraram que esses jogos podem ser percebidos como recursos significativos no desenvolvimento de habilidades distintas, ampliando, também, o conhecimento vocabular, além de proporcionar atitudes autônomas, considerando as estratégias de aprendizagem adotadas pelos gamers.
\end{abstract}

Palavras chave: Língua inglesa. Jogos eletrônicos. Narrativas de aprendizagem.

\section{Introdução}

Com a evolução tecnológica os jogos eletrônicos têm ocupado os mais distintos cenários, extrapolando o âmbito do entretenimento e abrangendo setores como publicidade, marketing, saúde e educação. As tecnologias digitais popularizaram o acesso a esses jogos, levando-os a fazer parte do nosso cotidiano, de maneira que, muitas vezes, jogamos sem ao menos perceber que estamos fazendo parte de um jogo.

Isso é possível devido ao fato de diversos aplicativos disponíveis nos aparatos tecnológicos, principalmente nos celulares, adotarem interfaces divertidas e interativas, fazendo com que atividades rotineiras se tornem mais atrativas, em decorrência do processo de gamificação, ou seja, da adoção das características do jogo em contexto de não jogo (ALVES, 2013; BUSARELLO, 2016).

\footnotetext{
* Doutoranda do Programa de Pós-Graduação em Educação na Universidade Federal de Alagoas (PPGE-UFAL). Mestre em Letras: Cultura, educação e linguagens. Professora Auxiliar da Universidade do Estado da Bahia.

** Doutora em Educação e em Linguística. Mestre em psicologia. Professora Associada I do Centro de Educação da Universidade Federal de Alagoas (UFAL). Docente do Programa de Modelagem Computacional do Conhecimento e do Programa de Pós-Graduação em Educação Brasileira- (PPGE - UFAL).
} 


\section{\#tear}

Os jogos eletrônicos ${ }^{1}$ têm sido apresentados em pesquisas recentes como instrumentos com aplicabilidades educativas significativas, salientando sua adoção no processo de aprendizagem de língua inglesa como destacado nos trabalhos de Guedes (2014), Leffa (2014), Leffa et al (2012), Reinders e Wattana ( 2011), Gee (2003), utilizados como aporte teórico neste estudo.

Ao tratar desse processo de inserção dos jogos eletrônicos e interfaces gamificadas em nossa prática diária, Leffa (2014) salienta que a escola também poderia se apropriar destes recursos, devido as suas potencialidades interativas e dinâmicas, assim como empresas têm adotado os games como forma de fidelizar e motivar os clientes.

No que tange aos games e aprendizagem da língua inglesa (LI), sabemos que muitos jogos demandam o conhecimento do inglês para serem jogados com eficiência exigindo habilidades para compreensão e execução de tarefas. Assim, a barreira linguística, algo que poderia desestimular os jogadores, acaba, em muitos casos, tornando-se fator motivador para aprender a língua e prosseguir no jogo, sendo a partir daí que muitos começam a criar estratégias próprias para compreender a LI e interagir com outros jogadores (GUEDES, 2014; LEFFA et al, 2012).

Considerando as distintas possibilidades de aprendizagem e entretenimento proporcionadas pelos jogos eletrônicos, este estudo foi motivado pela necessidade de analisar e compreender como ocorreu a aprendizagem da língua inglesa de estudantes gamers $^{2}$ por meio da prática de jogos digitais, especificamente o gênero MMORPG (Massive Multiplayers Online Role Playing Games) ${ }^{3}$, enfatizando as características que os tornam recursos eficientes à aprendizagem autônoma da LI, uma vez que, segundo Guedes (2014), vários praticantes assíduos de MMORPG atribuem seu conhecimento dessa língua ao contato com os jogos.

Para direcionar a pesquisa aqui retratada, partimos da seguinte pergunta: de que forma a prática de games do gênero MMORPG pode auxiliar no processo de aprendizagem da língua inglesa? Além de buscar responder ao questionamento, tenciona-se também, investigar os mecanismos e as estratégias utilizadas pelos aprendizes, destacando os recursos adotados para compreender o idioma, as principais características dos jogos utilizados e a postura dos jogadores frente à construção do seu conhecimento linguístico.

\footnotetext{
${ }^{1}$ Neste estudo jogos eletrônicos, jogos online, games e videogames serão tratados com o mesmo significado, podendo haver alternância entre os termos ao longo do texto.

${ }^{2}$ Para Harviainen et al (2015) o gamer é o indivíduo que exerce a prática com os jogos eletrônicos seja ocasionalmente ou com determinada frequência, mesmo que esse não se considere um jogador.

${ }^{3}$ Jogos Online de Interpretação em massa para múltiplos jogadores.
} 
Partindo da análise de narrativas de aprendizagem, propomos uma pesquisa qualitativa, configurada como estudo de caso, cujos participantes foram três estudantes de Letras/Inglês que afirmam terem aprendido a LI com jogos eletrônicos.

O estudo se justifica devido à necessidade de ampliar os referenciais nesse âmbito que, embora tenham crescido significativamente, ainda apresentam limitações principalmente quando se trata da inserção dos games como suporte à prática pedagógica docente em sala de aula.

\section{Considerações sobre os jogos eletrônicos}

Para adentrarmos em maiores considerações sobre os jogos eletrônicos e educação, faz-se pertinente apresentar o conceito de jogo no qual este estudo se fundamenta. Para tanto, partimos das considerações de Harviainen et al (2015) que percebem como jogo toda e qualquer atividade com regras coletivas, que apresente desafios, objetivos e resultados, sendo os jogos eletrônicos/digitais aqueles que podem ser jogados via computadores, smartphones, consoles ou qualquer outros dispositivos eletrônicos.

Para os autores, jogos desta natureza, são, dentre outras coisas: uma produção cultural como música, literatura e cinema; um hobby popular; uma fonte de histórias; uma ferramenta para criar suas próprias histórias; uma plataforma de interação social; um objeto de paixão e uma forma de expressar personalidade; uma inovação tecnológica; uma forma de trabalhar temas assustadores; uma atividade para toda a família; um equipamento esportivo e uma ferramenta útil para aprendizagem ou atividade física ${ }^{4}$.

Ainda fundamentando nos estudos de Harviainen et al (2015) e também em Gee (2003), podemos perceber que os jogos eletrônicos apresentam características positivas e também negativas no que diz respeito ao desenvolvimento humano, devendo estas características ser acompanhadas e observadas, principalmente quando tratamos de jovens e crianças.

Ao abordarmos os aspectos positivos destacamos: melhorias na coordenação motora; oportunidade de avaliar e processar uma grande quantidade de informação em curto período

\footnotetext{
${ }^{4}$ Tradução nossa

Digital games are:

Individual cultural pieces of work that are equivalent to movies; music and literature; A popular and useful hobby; A source of stories and a storyteller; A tool for creating own stories and play; A subject and a platform for social interaction; An object of passion and a way of expressing personality; Technological innovation; A way of dealing with frightening themes; A shared activity for the whole family; Sports equipment; Useful tools for learning or physical exercise.
} 


\section{\#tear}

de tempo antes de tomar uma decisão, o que também auxilia no desenvolvimento do raciocínio; rompimento de barreiras culturais, considerando que um jogo pode unir gamers de todo o mundo, sendo a língua inglesa utilizada como veículo de comunicação nessas situações; possibilidade de experimentar responsabilidades em grupos sociais diversificados, por meio da adoção de múltiplas identidades e ainda a superação do erros e desapontamentos (HARVIAINEN et al, 2015; GEE, 2003).

Ao tratar da relação do jogador com o ato de jogar, Quadros (2016) pondera que os jogos possibilitam que se experimente um mundo de fantasias no qual uma nova identidade é adotada, criando-se um eu idealizado que, muitas vezes, não é possível existir no mundo real, assumindo papéis e funções em um contexto alternativo. É por meio dessa nova identidade que ele experimenta essas oportunidades de mudança, incorporando as contribuições à sua realidade. Pode ainda acontecer o inverso, ou seja, a identidade do gamer, suas crenças e valores morais, interferirem nas atitudes do avatar/personagem e conduzirem suas ações dentro do jogo (GEE, 2003).

Com relação aos aspectos negativos, Harviainen et al (2015, p.103) destacam alguns sinais que devem ser observados para se verificar se o indivíduo está jogando em excesso ou não. Para melhor visualização, transformamos as informações evidenciadas pelos autores em questionamentos e apresentamos a seguir: o jogador passa muito tempo no computador ou console e esquece de fazer pausas? A falta do jogo causa desconforto e irritabilidade?A restrição de jogar causa reação emocional negativa? As relações fora do jogo são deixadas de lado ou reduzidas consideravelmente? Várias atividades deixam de ser feitas devido ao jogo? O jogo altera a frequência cardíaca?O jogo é motivo de ausências no trabalho ou escola? Outras formas de diversão são deixadas de lado por causa do jogo ? $^{5}$

Em caso de respostas afirmativas aos questionamentos, é perceptível que o jogo tem interferido negativamente na vida pessoal e social do indivíduo, devendo haver mudanças de postura.

Para Busarello (2016), as pessoas são levadas a jogar devido a quatro razões específicas: a) a necessidade de se obter domínio sobre determinado assunto, b) para aliviar o estress, c) para se entreter e divertir d) para socialização. Embora muitos associem a prática

\footnotetext{
5 Tradução nossa

Signs of excessive gaming:

The player spends a lot of time on the computer or console and forgets to take breaks; Lack of gaming causes restlessness and irritability; Restriction of gaming causes a strong negative emotional response; Relationships outside the game world are dismissed or narrowed down; considerably; Various duties are left unfulfilled due to gaming; Gaming disrupts the circadian rhythm; Gaming causes absences from school or work; Other hobbies are dismissed because of gaming.
} 
dos jogos com formas de isolamento, perda de tempo e fuga das práticas sociais devido às horas gastas diante das telas (GEE, 2003), alguns estudos como os de Santos (2011), Gee (2003) e Leffa et al (2012) os percebem como práticas sociais, nas quais há a necessidade de interação em grupos e divisão de trabalhos dentro dos "clãs", o que muitas vezes se torna uma maneira de fazer amizades dentro e fora do jogo.

Todavia nem todo tipo de jogo possibilita essa relação com outros sujeitos ocorrendo, principalmente, no gênero MMORPG por apresentar uma necessidade de interação e colaboração entre os jogadores para que as missões sejam concretizadas. Segundo Santos (2011, p. 16).

O MMORPG é um gênero de jogo de computador e ou videogame que permite que
seus jogadores criem e interpretem personagens em um mundo virtual dinâmico e
persistente compartilhado por centenas ou até milhares de jogadores
simultaneamente. Diferente dos games de outros gêneros, a maior parte da interação
ocorre com outros jogadores humanos e não com personagens controlados pelo
computador.

Complementando este conceito Leffa et al (2012, p. 219) consideram o videogame um gênero multimodal que apresenta como características centrais "ludicidade, interatividade, imprevisibilidade, suporte eletrônico e ação física do jogador", envolvendo elementos diversificados em sua prática. Em decorrência das possibilidades de interação entre os jogadores, os videogames tornam-se obras inacabadas, construídas colaborativamente pela ação e envolvimentos no desenrolar da narrativa, tirando os participantes da posição passiva de simples consumidores de entretenimento para transformá-los em autores/personagens da ação (SANTOS, 2011; LEFFA et al, 2012). Este fato corrobora a teoria de que as tecnologias modernas e a Web 2.0 dão aos usuários o poder de co-criação e interação com os recursos disponíveis em rede (DEMO, 2009).

Por demandar que o jogador se insira em uma comunidade com divisão de trabalhos, na qual todos desempenham funções específicas, os jogos de MMORPG exigem que haja parceria e colaboração, sendo necessário conhecimento do funcionamento da comunidade como um todo para que as missões sejam concluídas.

Sob esta perspectiva, considerando que o inglês é a língua oficial em grande parte dos jogos, para que esta interação ocorra, o gamer deve apresentar habilidades significativas neste idioma, no intuito de compreender as orientações, se comunicar dentro do jogo e cumprir as missões. O desconhecimento da LI, em determinadas situações, ao invés de impedir que o indivíduo jogue, acaba motivando-o a aprendê-la, superando suas dificuldades de compreensão ao buscar estratégias de aprendizagem que favoreçam e intensifiquem seu 
aprendizado (SANTOS, 2011; GUEDES, 2014). São estes aspectos que nos redirecionam à temática desta pesquisa e salientam a necessidade de se compreender como se dá este processo.

\section{Os jogos eletrônicos no âmbito educativo}

Segundo Alves (2008), os estudos abordando a relação entre jogos eletrônicos e educação têm início na década de oitenta destacando pesquisas que investigaram o desenvolvimento do raciocínio por meio de aparatos eletrônicos distintos. Embora a prática não seja recente, a utilização efetiva dos games no processo de aprendizagem ainda apresentam inúmeros desafios principalmente no que tange à preparação docente para atuar no contexto tecnológico contemporâneo.

Ao tratar do perfil do educador gamer, Harviainen et al (2015) ponderam que nem sempre o conhecimento aprofundado sobre jogos e cultura gamer é necessário, sendo mais relevante o interesse em educar por meio desses recursos. Os autores salientam ainda que este interesse pelo processo educativo é mais relevante que ser um expert em games, devendo-se considerar, também, o bem estar do aprendiz.

Com relação aos princípios de aprendizagem atribuídos aos videogames, Gee (2003) ressalta que a aprendizagem efetiva envolve o pensamento crítico e que os bons videogames podem encorajar um processo de construção do conhecimento ativo e crítico. O autor destaca que, ao aprendermos a jogar videogames, estamos também desenvolvendo novas práticas de letramento, devido ao contato com um gênero textual multimodal que requer a adoção de práticas de leituras diversificadas.

Para Gee (2003), se a criança ou o adulto estiverem jogando de forma a desenvolverem um processo de aprendizagem ativo e crítico, também estarão aprendendo a perceber o mundo sob outras perspectivas, mediante a inserção em novos grupos que oportunizarão práticas sociais diferenciadas associadas às novas identidades utilizadas dentro dos jogos.

Alves (2008) enfatiza ainda que a aprendizagem decorrida dos jogos eletrônicos ocorre devido ao significado atribuído às situações que emergem da narrativa e dos desafios presentes nos jogos, demandando letramentos múltiplos para compreensão e execução de tarefas.

Fazendo uma relação entre jogos e educação, em estudo realizado tratando dos games e a aprendizagem de LI, Leffa e Pinto (2014) destacam o potencial dos games em atrair a 
atenção do jogador. Para eles, essa característica dos jogos denominada estado do fluxo é “[...] exatamente o que queremos para a educação: alunos totalmente concentrados em suas atividades, esforçando-se ao máximo para superar seus limites” (LEFFA e PINTO, 2014, p. 368). Desta forma, é o estado de fluxo que faz a pessoa se distanciar do mundo real em uma aparente ausência ou distração, dado o grau de envolvimento que se encontra na atividade em curso (QUADROS, 2016), aspecto nem sempre alcançado por todos os alunos em sala de aula.

Embora muitos autores tratem das contribuições dos games para a aprendizagem, os estudos utilizados como aporte teórico nesta pesquisa não abarcam o contexto da sala de aula regular adotando os games como suporte pedagógico, mas sim, de situações diversificadas de aprendizagem que envolvem, em muitos casos, processos autônomos de construção do conhecimento, mostrando que há ainda carência de estudos que contemplem este âmbito.

\section{Jogos eletrônicos e aprendizagem de LI}

Em estudos recentes, os jogos eletrônicos, principalmente os videogames, têm sido percebidos como recurso eficientes para auxiliar no processo de aprendizagem da LI, apresentando contribuições significativas no desenvolvimento das quatro habilidades a saber ler, ouvir, falar e escrever.

Embora as músicas, filmes e séries também sejam instrumentos promissores para implementar a aprendizagem, os videogames se destacam abrangendo um público específico, os gamers, principalmente em estudos autônomos e informais da LI pois, ao interagirmos com este público, é comum ouvirmos jogadores assíduos afirmarem que aprenderam inglês devido à prática dos videogames (LEFFA et al, 2012; GUEDES, 2014; SERAFIN, 2016).

Segundo os autores citados, isso ocorre devido ao fato de muitos jogos apresentarem o inglês como língua oficial, requisitando conhecimento da LI para se jogar. Um fator relevante destacado por Guedes (2014) e Leffa et al (2012), ao tratar do processo de aprendizagem por meio dos games, é que o interesse do aprendiz/ jogador tanto pelo game quanto pelo idioma é fundamental. Ou seja, adotar os games como recursos de aprendizagem para um público que não se identifique com a prática dos referidos jogos pode não se mostrar um recurso eficiente.

Dada a variedade de aspectos envolvidos no ato de jogar e das distintas habilidades desenvolvidas em decorrência dos jogos eletrônicos (SERAFIN, 2016), os estudos utilizados para fundamentar esta pesquisa abrangem temáticas diversificadas como: análise do nível e da qualidade de proficiência adquiridas com os games, os tipos de interação em língua 
estrangeira que ocorrem ao longo de uma partida e as estratégias de aprendizagem adotadas pelos aprendizes para compreender informações em LI presentes desde os menus às missões proposta nos jogos (REIDERS e WATTANA, 2011; GUEDES, 2014; LEFFA et al, 2012; LEFFA, 2014).

Assim, ao tratar da utilização de jogos em processos de aprendizagem, Reiders e Wattana (2011) investigaram se há uma relação entre o ato de jogar e a interação na LI, procurando analisar a qualidade e quantidade das interações orais e escritas no referido idioma, ocorridas ao longo de seções de um jogo de MMORPG.

A pesquisa foi realizada com estudantes universitários da Tailândia, aprendizes de inglês como LE. Os resultados mostraram que a quantidade de ocorrência de interação ao longo do jogo foi ampla, porém, a análise qualitativa revelou que estas limitaram-se a sentenças simples, do tipo Yes/No questions e ao uso do presente simples principalmente nas interações orais via chat. Este estudo demonstrou que, embora sejam numerosas, as interações ocorridas durante um jogo nem sempre são significativas no que concerne ao processo de aprendizagem, o que não significa que impossibilite a comunicação entre os jogadores.

Ainda tratando da natureza e complexidade das interações em seções de jogos de MMORPG, Guedes (2014) investigou se um grupo de pessoas que aprendeu inglês via jogos eletrônicos conseguia se comunicar em contextos de não jogo. $\mathrm{O}$ foco da investigação foi analisar o que exatamente se aprende, em língua inglesa, com os jogos e as possibilidades de se comunicar utilizando os insumos adquiridos. A autora partiu da hipótese de que o que se aprende no jogo, em nível linguístico, não é suficiente para que o jogador interaja em outros contextos. Entretanto, após realização de entrevistas comprovando níveis de proficiência diversificados entre os participantes, os resultados mostraram que os informantes estavam aptos a se comunicar com fluência em língua inglesa.

A aprendizagem da LI por meio dos jogos torna-se possível porque, além de favorecer o contato com vocabulário amplo, a prática dos MMORPG insere o aprendiz/jogador em um contexto que requer a utilização da língua em situações semelhantes à acontecimentos reais, levando-o a experienciar um ambiente de imersão ao tornar-se membro de uma comunidade virtual.

Desta forma, mesmo que a princípio os jogadores comecem traduzindo palavras ou pequenas sentenças, com a prática, começarão a associá-las aos contextos atribuindo sentido às expressões, de forma que também possam ser utilizadas em situações extra jogo (LEFFA, et al, 2012). 


\section{\#tear}

Para Serafin (2016), a aquisição de uma segunda língua por meio dos jogos eletrônicos é interativa, eficaz e criativa, expondo o aprendiz a insumos autênticos que viabilizam, principalmente, o desenvolvimento de vocabulário e pronúncia. Porém, por considerar que as práticas linguísticas presentes nos jogos apresentam um alto nível de informalidade, o autor reforça a necessidade de associar este tipo de aprendizagem a insumos linguísticos formais.

Tendo em vista que este processo de aprendizagem ocorre devido às distintas situações vivenciadas nos jogos, amparados em desafios e conflitos a serem superados, Guedes (2014), ao citar os estudos de Schell (2008), faz uma comparação entres os aspectos presentes nos jogos e o desafio em se aprender uma língua estrangeira conforme adaptado e apresentado no quadro abaixo.

Quadro 1- Comparação entre desafios presentes nos jogos e na aprendizagem de línguas

\begin{tabular}{|c|c|c|}
\hline Desafios & Games & Aprendizagem de línguas \\
\hline Voluntariedade & $\begin{array}{l}\begin{array}{l}\text { Deve-se começar } \\
\text { espontaneamente, } \\
\text { voluntária. }\end{array} \text { de } \\
\begin{array}{l}\text { maneira } \\
\text { mogo, }\end{array}\end{array}$ & $\begin{array}{l}\text { O interesse em aprender uma nova língua } \\
\text { deve partir voluntariamente do aprendiz. }\end{array}$ \\
\hline Objetivos & $\begin{array}{l}\text { Todo jogo possui objetivos (missões) a } \\
\text { serem alcançados e atingidos, } \\
\text { superando-se etapas. }\end{array}$ & $\begin{array}{l}\text { É fundamental que se tenha objetivos de } \\
\text { aprendizagem claros e definidos a serem } \\
\text { atingidos. }\end{array}$ \\
\hline Conflitos & $\begin{array}{l}\text { Os conflitos são definidos pelas } \\
\text { dificuldades encontradas (e superadas) } \\
\text { ao longo do jogo que devem apresentar } \\
\text { nível de dificuldades gradativo e } \\
\text { equilibrado. }\end{array}$ & $\begin{array}{l}\text { O processo de aprendizagem envolve } \\
\text { níveis de dificuldades (básico, } \\
\text { intermediários, avançado etc) que devem } \\
\text { ser inseridos gradativamente com base } \\
\text { no conhecimento adquirido pelo } \\
\text { aprendiz. }\end{array}$ \\
\hline Regras & $\begin{array}{l}\text { Todo jogo possui regras a serem } \\
\text { seguidas para que os objetivos sejam } \\
\text { alcançados }\end{array}$ & $\begin{array}{l}\text { Ao longo do processo de aprendizagem } \\
\text { existem regras a serem seguidas para que } \\
\text { a aprendizagem ocorra como realização } \\
\text { de tarefas, compromisso com os estudos } \\
\text { etc. }\end{array}$ \\
\hline
\end{tabular}

Fonte: Adaptado de Guedes (2014)

Neste quadro comparativo a autora nos mostra a relação existente entre o que é vivenciado nos jogos e o processo de aprendizagem de LI. Dentre os pontos destacados no quadro, é pertinente enfatizar, principalmente, a voluntariedade que deve existir ao propor atividades com jogos eletrônicos em contextos educativos, pois, conforme salienta Leffa et al (2012, p. 226 ) não se trata da simples utilização de um recurso como suporte para a 
aprendizagem e sim de “[...] transformar o lazer, que é a finalidade do jogo, em um meio para um fim diferente, que é a aquisição da língua"

Considerando que muitos games atualmente já apresentam suas versões dubladas ou legendadas em vários idiomas, o contato com a língua inglesa, até determinado ponto, tornase opcional. É certo que o conhecimento da LI proporcionará ao jogador contato e interação com gamers de diferentes lugares do mundo que utilizam este idioma para a comunicação conforme pondera Guedes (2014), entretanto, as opções de dublagem e legendagem possibilitam a execução do jogo, sem maiores impedimentos linguísticos, mesmo que de forma limitada. Ao optar pelo jogo em sua versão original, consoante Leffa et al (2012), os objetivos dos jogadores já não se limitam ao simples ato de jogar, sendo agregados, também, objetivos de aprendizagem da língua.

Sem o desejo de aprender, os videogames tornam-se apenas diversão assim como filmes, séries, músicas e outra gama de recursos não pedagógicos disponíveis em rede que podem ser adotados com fins educativos de maneira igualmente eficiente. Partindo da premissa que esse desejo em aprender a LI nem sempre está presente nos gamers, ao tratarmos de processos de aprendizagens com a utilização de jogos eletrônicos, faz-se relevante abordar questões referentes à aprendizagem incidental, uma vez que muitos jogadores estão interessados apenas em cumprir missões e avançar no jogo, sendo a aprendizagem da língua inglesa apenas uma consequência do ato constante de jogar, que ocorre de forma não intencional.

Para Vazquez et al (2014), o processo de aprendizagem incidental abarca situações de aprendizagem informais e não planejadas, envolvendo a construção do conhecimento fora de uma ambiente de instrução formal, porém sem haver a intenção em aprender. Os autores ressaltam ainda que não se trata de um simples processo de exposição a determinadas situações e sim algo que surge de maneira inesperada partindo de um determinado contexto, situado socialmente, levando o sujeito a agir sob pressão, à exemplo do que ocorre com alguns jogadores ao aprenderem a LI em decorrência da prática dos games.

\section{Metodologia}

Conforme destacamos na seção introdutória, esta pesquisa tem por objetivo investigar como ocorreu o processo de aprendizagem da LI de aprendizes gamers, partindo da prática de jogos eletrônicos, mais precisamente os do gênero MMORPG. 
A motivação para o estudo se ampara na necessidade de se compreender as potencialidades dos videogames enquanto recurso de aprendizagem. Para tanto partimos do seguinte questionamento: de que forma a prática de games do gênero MMORPG pode auxiliar no processo de aprendizagem da língua inglesa? Objetivamos, também, observar as estratégias de aprendizagem adotadas pelos aprendizes/jogadores para desenvolverem suas habilidades linguísticas no idioma, bem como a postura adotada frente seu processo de aprendizagem e os recursos utilizados.

Os participantes do estudo foram três estudantes de Letras/inglês que afirmam terem aprendido o idioma por meio dos jogos eletrônicos, somando-se aos conhecimentos adquiridos na escola regular. Os sujeitos investigados apresentam faixa etária entre 19 e 20 anos, sendo dois homens e uma mulher e destacam terem iniciado a prática com os games desde a infância, transitando por outros gêneros até chegar aos MMORPG. Por questões éticas, os sujeitos serão identificados na pesquisa com nomes fictícios de sua escolha, a saber, Heisenberg, Mel e DasTik.

$\mathrm{O}$ estudo se configura como uma pesquisa qualitativa na modalidade estudo de caso tencionando analisar e compreender as experiências dos sujeitos, partindo dos contextos no quais estas foram vivenciadas (YIN, 2003, ANDRÉ, 2003), neste caso, o contexto dos games como ambiente propício para construção do conhecimento.

Os dados foram coletados por meio de narrativas de aprendizagem solicitadas aos participantes via email. As narrativas de aprendizagem têm sido utilizadas como instrumento eficiente para coleta de dados em pesquisas qualitativas recentes, constituindo-se um meio para reflexão do processo ensino e aprendizagem e das experiências dos aprendizes ao narrar e revisitar suas histórias de vida (LIMA, 2010; MUYLAERT et al, 2014). Cabral e Souza (2015, p.150) percebem as narrativas como uma forma de "[...] contar e revelar o modo pelo qual os sujeitos concebem e vivenciam o mundo", tornando-se recursos pertinentes para análise de experiências vividas, a exemplo dos processos de aprendizagem.

Embora tenha sido solicitada uma narrativa livre abordando a trajetória de aprendizagem da LI, destacando o papel desempenhado pelos games neste processo, algumas questões norteadoras foram apresentadas como sugestão aos participantes, tencionando auxiliar a escrita dos textos.

Para conduzir a análise estabelecemos quatro critérios, tendo por base os objetivos de estudo propostos. Assim, pretendemos analisar: a) as formas de contato com a LI no jogo; b) as estratégias utilizadas para compreender o idioma; c) as habilidades linguísticas 


\section{\#tear}

desenvolvidas com a prática dos jogos e d) os posicionamentos dos participantes sobre a relação entre os jogos e aprendizagem de LI.

Os critérios foram dispostos e analisados nesta ordem de forma que possamos estabelecer uma trajetória no processo de aprendizagem dos participantes. Assim, primeiramente mostraremos de que forma eles foram expostos ao contato com a LI durante as partidas dos jogos, em seguida abordaremos as estratégias utilizadas para compreender esses insumos linguísticos, destacando as habilidades desenvolvidas e por último observaremos as opiniões e relações que os participantes estabelecem entre os games e a aprendizagem de LI.

\subsection{Análise dos dados}

\subsubsection{As formas de contato com a língua inglesa no jogo}

Ao tratarmos das formas de contato com a LI proporcionadas pelos games, percebemos que estas ocorreram de várias maneiras, seja por meio dos textos escritos apresentando direcionamentos para as missões a serem cumpridas, orientações nos menus dos jogos, palavras e frases que aparecem ao longo das partidas e ainda os insumos verbais, orais ou escritos, provindos da comunicação via chats. Estes aspectos podem ser percebidos nos excertos apresentados abaixo.

Mel: [...] os jogos eram em língua inglesa, e para entender a história e poder jogar eu deveria entender o que estava escrito e o que estava sendo falado pelos personagens e narradores dos jogos, ou até mesmo informações em menus [...] os jogos não possuíam legendas em língua portuguesa e nem eram dublados, o máximo que havia eram legendas na própria língua inglesa, e isso me motivava a aprender novas palavras em língua inglesa [...] fui melhorando o meu inglês pesquisando as palavras que não conhecia, mas que precisava saber o significado [...] Mesmo que você não tenha conhecimento destas palavras em inglês, com o passar do tempo, conforme você vai ouvindo, você acaba ligando estas frases com as ações que acontecem simultaneamente no jogo, e começa a entender o que aquelas palavras significam.

DasTik: Com meus dez anos, ganhei meu primeiro computador, me levando assim para um novo mundo de jogos. Jogos de aventura, exploração, terror, enfim, jogos mais complexos e que sem o entendimento do inglês ficavam um pouco mais difíceis de serem entendidos e até mesmo de serem jogados, pois, em alguns casos, dicas de o que seria necessário para passar de determinada fase, eram dados em forma de texto ou diálogos falados.

Heisenberg: O inglês aparece na minha vida através dos jogos de MMORPG, (principalmente o Lineage II) que são jogos multiplayer online e nesses jogos você tem a capacidade de se comunicar com qualquer pessoa em qualquer lugar do mundo pelo chat do próprio jogo, em MMORPGs, você cria e controla um personagem, e ao decorrer do jogo, é preciso fazer várias missões para avançar na aventura, essas missões se tornavam ainda mais difíceis pelo fato de estarem em inglês. 
Com a leitura das falas dos participantes, observamos que os jogos por eles utilizados favorecem um contexto de imersão e exposição a referenciais linguísticos autênticos na LI. Para Serafin (2016), este contato pode enriquecer o vocabulário e implementar melhorias na pronúncia, permitindo a utilização de uma linguagem autêntica que nem sempre ocorre no contexto da sala de aula. Mesmo que a princípio não compreendam todas as informações, ao associar com as ações do jogo, conforme destaca a informante Mel, o conhecimento pode ocorrer por meio da dedução do significado.

É importante evidenciar, conforme pondera Leffa et al (2012), que a aprendizagem de uma língua não deve se limitar a palavras e frases isoladas, e, sim, saber utilizar esses insumos dentro de um contexto. Para os autores, a prática dos games além de proporcionar um processo de aprendizagem contextualizado, permite ainda que o aprendiz vivencie novas identidades e experiências nem sempre possíveis em seu mundo real.

Dessa forma, compreender a LI é fator relevante para os gamers uma vez que o mundo vivenciado por eles dentro dos jogos demanda este conhecimento linguístico. Observaremos a seguir como os participantes fizeram para alcançar essa compreensão e quais as estratégias e recursos utilizados por eles ao longo desse processo de construção do conhecimento.

\subsubsection{Estratégias utilizadas para compreender idioma}

Embora os estudos sobre estratégias de aprendizagem não sejam recentes, estas desempenham um papel importante na construção do conhecimento dos estudantes, caracterizando, também, um reflexo da autonomia dos estudantes ante o seu processo de construção do conhecimento. O conceito de estratégias adotado neste estudo é o de Oxford (1990) que as percebe como as ações adotadas pelos aprendizes para solucionar possíveis dúvidas e problemas, no intuito de facilitar a sua aprendizagem ou possibilitar que ela ocorra.

Segundo Coscarelli (1997), o trabalho com as estratégias é fundamental para se formar um aprendiz autônomo, posto que ele mesmo terá condições de identificar suas dificuldades de aprendizagem por intermédio da constante autoavaliação. Este pensamento corrobora o de Zacharias (2016) ao considerar que o contexto tecnológico e as novas possibilidades de aprendizagem descentralizam o docente e permite que os aprendizes sejam mais participativos em seus processos educativos.

Como podemos acompanhar nos excertos que se seguem, os participantes ao identificarem suas dificuldades de compreensão, buscaram meios de sanar os problemas e dirimir suas dificuldades. 
Mel: Sempre que eu ouço alguma palavra diferente ou alguém me envia alguma mensagem com alguma expressão que eu não conheço eu logo vou pesquisar o significado, geralmente utilizo o Google tradutor ou coloco a expressão no site de pesquisas [...] muitas vezes de acordo com a cena ou ação que o personagem está realizando dá para compreender o que a palavra ou frase quer dizer [...] sempre que o personagem do jogo está falando eu tento acompanhar a legenda para saber o que aquela palavra significava[...].

DasTik: [...] ficava tentando várias vezes, até conseguir passar. Mas, com isso, da próxima vez que aquela palavra aparecesse eu já saberia o que teria que fazer. [...] Algumas vezes eu anotava algumas palavras em inglês para lembrar o que cada uma significava. [...] Notei que era mais fácil conversar em inglês com falantes não nativos do que com nativos pois, por também estarem "aprendendo" a língua, falavam mais devagar e sem usar muitas gírias.

Heisenberg: [...] na época era meio difícil conseguir traduzir todos aqueles textos, então eu tinha que me virar, relacionando o que estava escrito nas missões com o que acontecia no jogo e assim aprendendo involuntariamente novos vocabulários no idioma [...]as vezes eu fazia o uso de sites, blogs ou fóruns em português que explicavam como fazer as Quests do jogo.

Ao analisar as estratégias adotadas pelos participantes, observamos que o contexto do jogo é um recurso muito utilizando para deduzir significados, relacionando palavras e textos a situações e acontecimentos, ou repetindo ações até alcançar o resultado almejado. Outra estratégia recorrente é a tradução de textos e palavras. Mel e DasTick salientam que tomam notas de palavras e expressões desconhecidas para pesquisar em tradutores e saberem seus significados da próxima vez em que aparecerem no jogo.

Além dessas estratégias, outro recurso identificado como instrumento para auxiliar na compreensão dos games e da LI é a consulta aos blogs e fóruns que tratam de jogos. Segundo Harviainen et al (2015) esses blogs associados à cultura gamer, seja por meio de vídeos, animações ou textos, discutem vários aspectos relacionados aos jogos eletrônicos, compartilhando informações sobre personagens, desafios, níveis, dentre outros aspectos, auxiliando os jogadores a sanarem dúvidas recorrentes, possibilitando a compreensão de expressões e dicas apresentadas em língua inglesa.

A autonomia e autoavaliação são fatores preponderantes na adoção de estratégias, já que, ao identificar as suas dificuldades, o estudante saberá buscar os recursos mais propícios para auxiliá-lo. Percebemos estas características na fala de DasTick, ao identificar que a comunicação com falantes não nativos era "fácil" por falarem mais "devagar" e "usarem menos gírias", tratando de uma estratégia eficiente para auxiliar no desenvolvimento de suas habilidades comunicativas, o que também requer maturidade do aprendiz em identificar o grupo que melhor atende suas necessidades.

Por meio do contato com os jogos Serafin (2016) e Guedes (2014) enfatizam que várias habilidades vão sendo desenvolvidas como resultado da construção do conhecimento 


\section{\#tear}

no idioma. Destacamos a seguir quais as habilidades linguísticas foram estimuladas nos aprendizes/ jogadores.

\subsubsection{Habilidades linguísticas desenvolvidas com a prática dos jogos}

Notamos nas falas dos participantes que a prática dos jogos estimulou significativamente o desenvolvimento das habilidades linguísticas. Em seus estudos, Serafin (2016) destaca que o contato com a LI, realizado de maneira diversificada, permite que o gamer possa ler, ouvir, escrever e falar em língua inglesa durante uma partida.

Porém, não significa que as habilidades serão desenvolvidas necessariamente com a mesma intensidade, por exemplo, o jogador que não se sentir apto para conversar oralmente com os outros gamers, pode se limitar ao uso do chat via mensagens escritas. Isto implicará em maior desenvolvimento da escrita em detrimento da oralidade, uma vez que é esta habilidade que está sendo posta em prática com maior incidência.

As falas dos participantes, no entanto, evidenciam que estes se propuseram ao desenvolvimento das suas distintas habilidades, buscando contato com o idioma em suas diversas modalidades.

Mel: Os jogos atuais são em sua maioria dublados ou legendados [...], mas há a possibilidade de jogar online em modos multiplayers, e isso faz com que possamos ter contato com pessoas do mundo inteiro [...] mais interessante disso é que utilizamos a língua inglesa para podermos nos comunicar através de mensagens dentro do jogo [...] O fato de jogar e se comunicar com pessoas que falam a língua inglesa faz também com que aprimoremos nosso vocabulário, geralmente iremos ouvir expressões entre outras coisas que não ouviremos numa sala de aula por exemplo.

DasTik: Uma das ferramentas que mais me fizeram aprender o inglês foi o programa chamado "teamspeak (TS)" que basicamente é uma sala de chat por voz para você poder jogar com o seu time. Independente do jogo, usar o TS era algo para conversar com os amigos e as vezes apareciam alguns americanos e sempre tentava falar pelo menos o básico com eles.

Heisenberg: [...] ao mesmo tempo ia assimilando o que lia no fórum com o que estava escrito no jogo, isso me ajudou bastante na leitura e escrita em inglês, pois tinha que ler as Quests e me comunicar com outros jogadores que na maioria das vezes era em inglês. [...] Não foi exatamente o jogo Dota 2 em si, e sim as transmissões dos campeonatos, onde os narradores falavam somente em inglês, e com isso, todos os dias eu tinha esse contato com o idioma e ia aprendendo involuntariamente o sotaque, as gírias, o ritmo da fala, vocabulário, estrutura das frases, e foi assim que aprendi inglês.

Nos excertos mostrados, a habilidade de leitura dos participantes foi desenvolvida e estimulada devido ao contato com palavras e expressões que, como destacado anteriormente, foram registradas pelos jogadores para pesquisa de significado, o que também auxiliou no desenvolvimento vocabular. Durante o jogo a leitura também é realizada nos quests, ou 


\section{\#tear}

missões, conforme destacado por Heisenberg. O chat por mensagem de texto torna-se recurso para prática de escrita em LI, aliando-se aos fóruns e blogs utilizados para comunicação e resolução de questões referentes aos jogos.

As comunicações orais via chat proporcionaram o desenvolvimento das habilidades de ouvir e falar. Mel destaca que uma das contribuições deste contato oral com a língua por meio dos jogos é o fato de aprender expressões que comumente não são contempladas em sala de aula. DasTick ressalta que, mesmo sem amplos conhecimentos da LI, sempre tentava se comunicar em chats com americanos. Já Heisenberg salienta que as narrações dos jogos foram instrumentos relevantes no desenvolvimento da sua fala, partindo do que ouvia nas narrações.

\subsubsection{Posicionamentos e opiniões sobre jogos e aprendizagem de LI}

Com relação aos posicionamentos e opiniões dos participantes sobre os games e a aprendizagem da LI, fica evidente que eles reconhecem tanto a relevância da língua inglesa no mundo dos jogos, como também, o papel dos jogos em seu processo de aprendizagem conforme apresentados nos excertos a seguir.

Mel: Mesmo sendo de países em que a língua inglesa não é a primeira língua, essa é a língua utilizada para se comunicar, e por isso é necessário saber inglês [...] e como iremos sempre nos deparar com jogadores que falam a língua inglesa, aprimorar o nosso conhecimento do inglês se torna importante e melhora a nossa experiência dentro do jogo. [...] Sou uma apaixonada por jogos e isto de certa forma dá uma motivação a mais para poder buscar entender o que está sendo dito no jogo.

DasTik: O mundo dos jogos realmente me fez aprender a língua, mas não foi algo rápido ou esperado, aconteceu aos pouco e sem nenhuma pressão. Só apenas depois de 10 anos que realmente vi que meu inglês estava em um nível avançado [...] a comunicação em jogos online é uma grande ferramenta que poderia ser explorada com esse intuito de ensino e aprendizado de língua [...] Mas aprender inglês nunca foi o foco da jogatina, foi algo adquirido ao passar dos anos [...] A partir do momento que vi que meu inglês estava começando a ter um nível um pouco melhor decidi entrar em salas americanas do TS para tentar aprender ainda mais conversando com nativos ou pessoas que falassem inglês.

Heisenberg: Mas foi com o jogo Dota 2 que meu inglês melhorou bastante em todos os aspectos, e me ajudou imensamente a chegar no que eu considero hoje de fluência, pois consigo compreender e me comunicar sem problema algum com falantes da língua inglesa.

Ao destacar que a língua inglesa é utilizada nos games por falantes de todo o mundo possibilitando um contato com diferentes aprendizes, sotaques, expressões, Mel destaca que o fato de saber o idioma melhora a experiência com o jogo. Outro aspecto interessante destacado por esta participante é o fato de se dizer "apaixonada por jogos" e essa paixão motivá-la a aprender a língua para compreender o que está sendo dito, reafirmando o 
pensamento de Leffa et al (2012) de que o desejo de aprender é fundamental ao utilizar os jogos como mediação da aprendizagem.

Se o estudante/gamer não se interessar pelo jogo em si, nada garante que ele passará horas tentando entender os textos que aparecerem na tela em uma narrativa, na maioria dos casos, longa e complexa, pois segundo Gee (2003), um bom jogador pode levar de 5 a 10 horas para finalizar um jogo. No caso da informante Mel, embora o desejo não seja o de aprender o idioma a princípio, a paixão pelos jogos a conduz para este objetivo.

O participante DasTick, ao descrever seu processo de aprendizagem, deixa evidente que, apesar dos jogos constituírem instrumentos significativos para mediar a aprendizagem, trata-se de um processo lento, que demanda tempo e dedicação. O gamer destaca ainda que só após 10 anos de prática com os jogos reconheceu um nível avançado de seu conhecimento do idioma, devido às habilidades comunicativas desenvolvidas em constantes práticas de conversação com falantes nativos ou não.

Um aspecto relevante destacado por DasTick é o fato de afirmar que "aprender inglês nunca foi o foco da jogatina" e sim algo que foi construindo ao longo dos anos, o que nos leva a inferir que, no início, o seu processo de aprendizagem ocorreu de maneira incidental, ou seja, de forma não intencional ou planejada, em decorrência de outra atividade que, neste caso, foi a prática dos games (VAZQUEZ et al, 2014). Entretanto, observamos em sua fala que, posteriormente, ao perceber o desenvolvimento das suas habilidades, o aprendiz/jogador começou a investir conscientemente em sua aprendizagem adotando estratégias que melhor o auxiliasse no percurso.

O participante Heiserberg, destaca que a prática dos jogos foi de suma importância em seu aprendizado e fluência, uma vez que se considera apto para comunicar com falantes da LI.

Constatamos, assim, que a relação estabelecida pelos participantes entre os games e a língua inglesa foi sumamente positiva, salientando que o processo de aprendizagem mediado por este instrumento é lento e requer tempo e dedicação por parte do aprendiz /jogador.

\section{Considerações finais}

Vários estudos despontaram nos últimos anos ressaltando as virtudes do uso de jogos eletrônicos na aprendizagem de línguas, sinalizando-os como recursos promissores neste contexto. Amparada nesses estudos, a pesquisa teve como objetivo analisar de que forma os jogos eletrônicos podem auxiliar no processo de aprendizagem da LI e também investigar as estratégias adotadas pelos aprendizes/jogadores frente a sua aprendizagem. 
Após análise das narrativas, foi possível destacar que, motivados primeiramente pela vontade de jogar, os aprendizes adotaram estratégias que julgaram significativas para sua aprendizagem como a utilização de tradutores, registros de palavras, recorrência a blogs e fóruns sobre jogos, práticas de conversação, com falantes nativos ou não, para desenvolver suas habilidades e superar a barreira linguística.

Ficou evidente uma postura ativa e autônoma adotada pelos jogadores/aprendizes, buscando sempre recursos que pudessem sanar suas dúvidas sobre os jogos e, por consequência, proporcionar o aprendizado. Percebemos assim, que os games podem ser considerados instrumentos que estimulam o desenvolvimento das quatro habilidades (ler, ouvir, falar e escrever) como também auxiliam na aquisição de pronúncia e vocabulário. $\mathrm{O}$ desenvolvimento destas habilidades torna-se possível em decorrência dos contextos dos jogos que inserem o aprendiz em um mundo alternativo, demandando tomada de decisões e interação entre os participantes em um ambiente colaborativo.

Convém salientar que, ao iniciar a prática da LI por meio dos games, a motivação primeira destacada pelos participantes deste estudo é a superação dos desafios e missões presentes nos jogos, na sua condição de atividade de entretenimento, sendo a aprendizagem da LI uma proposição secundária. Portanto, ao pensar em processos de aprendizagem por meio dos jogos, é preponderante investigar, antecipadamente, as afinidades do público com essa modalidade por envolver um processo gradativo que requer uma postura ativa do aprendiz/jogador.

\title{
FROM START TO GAME OVER: ANALYSING ENGLISH LEARNING NARRATIVES WITH ELECTRONIC GAMES.
}

\begin{abstract}
This study aims to investigate the learning process of english language (EL) students, who assume that they have learned the language through the practice of electronic games, specifically the so-called MMORPG games, and also highlight the strategies adopted by learners throughout this process. This is a qualitative research that had as participants three students of letters/english, gamers. To collect the data, learning narratives were used in which the learners reported their process of knowledge construction in EL, starting from the contact with the games. The research was based on the following question: How can MMORPG games help in the English language learning process? The results showed that these games can be perceived as significant resources in the development of different abilities, also improving vocabulary knowledge, besides providing autonomous attitudes, considering the learning strategies adopted by the gamers.
\end{abstract}

Keywords: English language. Electronic games. Learning narratives. 


\section{Referências}

ALVES, L. Relações entre os jogos digitais e aprendizagem: delineando percurso. Educação, Formação \& tecnologias; vol.1,n 2, p. 3-10, nov. 2008.

Games e educação: desvendando o labirinto da pesquisa. Educação e

Contemporaneidade, Salvador, v. 22, n. 40, p. 177-186, jul./dez. 2013.

ANDRÉ, M. E. Etnografia da prática escolar. 9ª ed. Campinas: Papirus, 2003.

BUSARELLO, R. I. Gamification: princípios e estratégias. São Paulo: Pimenta Cultural, 2016.

CABRAL, C.L.O.; SOUZA, M.G.S. A narrativa como opção metotodológica de pesquisa e formação de professores. Horizontes, v.33, n²,p.149-158,jul/dez. 2015.

COSCARELLI, C. V. Estratégias de aprendizagem: uma breve introdução. Edutec.

Tecnologia. Belo Horizonte, v.4, n 4, p.23-28, jan/jul. 1997.

DEMO, P. Educação Hoje: Novas tecnologias, pressões e oportunidades. São Paulo: Atlas, 2009.

GEE, J. P. What video games have to teach us about learning and literacy. New York: Palgrave Macmillan, 2003.

GUEDES, L. K. O uso de Games como input para a aprendizagem de línguas. Anais do Congresso Ibero americano de Ciências, Tecnologia, innovación y Educaión. Buenos Aires, 2014. Disponível em http://www.oei.es/historico/congreso2014/25memorias2014.php Acesso em: outubro, 2017.

HARVIAINEN, J.T. et al. (edit.) The game educator's handbook E-book disponível em: http://www.pelikasvatus.fi/gameeducatorshandbook.pdf, 2015

LEFFA,V. J.; BOHN, H. I.; DAMASCENO,V. D.; MARZARI G. Q. Quando jogar é aprender: o videogame na sala de aula. Rev. Est. Ling., Belo Horizonte, v. 20, n. 1, p. 209230, jan./jun. 2012.

; PINTO, C. M. Aprendizagem como vício: o uso de games na sala de aula.

Revista (Con)textos linguísticos, Vitória, v.8, n 10.1,p.358-378, 2014.

LIMA, D.C L.(Org.) Aprendizagem de língua inglesa: histórias refletidas. Vitória da Conquista, Edições UESB, 2010.

MUYLAERT, C. J.; SARUBBI, V. J.; GALLO, P.R.; NETO, M. L.R. Entrevistas narrativas: um importante recurso em pesquisa qualitativa. Rev. Esc Enferm USP, p.193-199, 2014

OXFORD, R. Language learning strategies: what every teacher should know. Heinle \&Hinle, 1990. 
REINDERS, H.; WATTANA, S. Learn english or die: the effects of digital games on interaction and willingness to communicate in a foreign language. Digital Culture \& Education, $p$. 3-29, 2011.

QUADROS, G. B. A gamificação no ensino de línguas online. Tese (Doutorado). Programa de pós-graduação em Letras. UCPEL, 2016. Disponível em: pos.ucpel.edu.br/dissertacoesppgl/?action=download\&file. Acesso em: 20/10/17.

SERAFIN, M. The influence of computer games on second language acquisition.

Edutainmente Issue, p.79-86, 2016.

SANTOS, V. R. Os jogos de MMORPG como auxiliares no processo de aquisição da língua inglesa. Dissertação (mestrado) Programa de pós-graduação em Estudos linguísticos. UFMG, 2011. Disponível em: www.bibliotecadigital.ufmg.br/dspace/handle/1843/DAJR8GLRA7. Acesso em: 05/11/17

VAZQUEZ, A.C.; RUAS,R.L.; CERVO, C.S.; HUTZ,C.S. An "adventure" of MBA in Europe: How volcanic ash produced an incidental learning experience. Educational research and reviews, v.9,118-129, fev, 2014.

YIN, R. K. Case study research: design and methods. Sage publication, Thousand Oaks, California, 2003.

ZACHARIAS, V.R. Letramento digital: desafios e possibilidades para o ensino. In COSCARELLI, C. V. (Og.). Tecnologias para aprender. 1.ed. São Paulo: Parábola, p.15-29, 2016. 